\title{
Turtle and Teacher
}

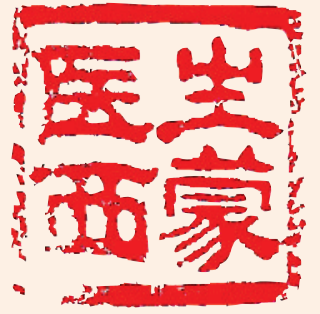

Many, many years ago, by the banks of the river 河 JO LAN («sword lily») in the province of DA in the great Empire of China, Teacher 教 师

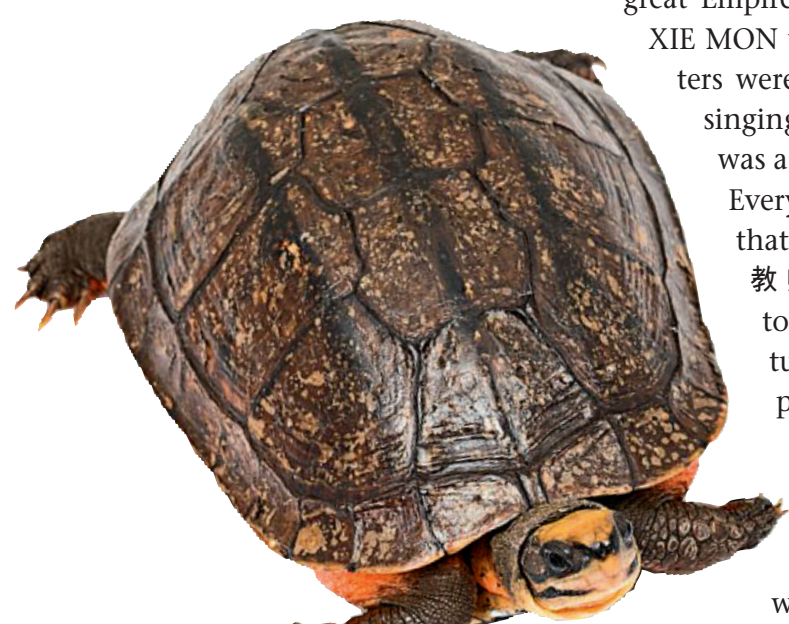
running the birds were singing sweet tunes and there was a feeling of peace in the air. Everything was so marvelous, that we suppose the fisherman 教师 XIE MON surely arrived to the highest level of spirituality; the level of inner peace. This happened because 教师 XIE MON was not a simple fisherman, but in reality he was one of the most well-known philosophers. Nearby a big turtle asked him if he was able to understand the language of the animals. 教师 XIE MON confirmed this and explained to the turtle why the sages are able to do this.

«Once upon a time, animals and men were beings with the same conscience but a different appearance and voice. These signs, of the same identity of conscience and mental similarity, remain to this day, so it is possible for some sages or philosophers to understand animal speech. The signs of mental similarity
Eisfeldstrasse 22 CH-8050 Zürich are that both animals and humans try to protect their life and remain in good health. They also procreate in the same way. The animal young and human babies remain with their mother after birth. Both animals and human beings avoid the open plains and prepare for themselves a dwelling in the den, nest or shelter in their houses. In the same way they both avoid cold places and search for sunshine.

Animals and humans live in society; animals in herds, humans in families. When the herds move, the youngsters are in the middle with the adults protecting them in the outer circle. Soldiers at war protect their comrades in the same way. Animals and humans gather together to drink, animals at their waterholes and humans in tea houses. When they find new food sources they inform each other and take the food either to their den or from the markets to their homes as the case may be. For the sages only the identity of conscience of the animals is important, not their appearance or their voices. This identity once equal and now similar permits the sages to understand the animal speech.»

This tale is based on an ancient Chinese silk inscription. The tale is dedicated to Charles Darwin, on the occasion of the bicentenary of his birth(12.2.1809) and the 150 th anniversary of publication of his seminal work «On the origin of Species». 